\title{
The Effect of Macroeconomic Instability on Economic Growth in Iran
}

\author{
Hassan Karnameh Haghighi ${ }^{1, *}$, Majid Sameti ${ }^{1} \&$ Rahim Dallali Isfahani $^{1}$ \\ ${ }^{1}$ Dept. of Economics, University of Isfahan, Isfahan, Iran \\ *Corresponding author: Hassan Karnameh Haghighi, Dept. of Economics, University of \\ Isfahan, Isfahan, Iran. E-mail: Karnameh@yahoo.com
}

Received: March 19, 2012 Accepted: May 21, 2012 Published: September 10, 2012

doi:10.5296/rae.v4i3.2393 URL: http://dx.doi.org/10.5296/rae.v4i3.2393

\begin{abstract}
Effect of macroeconomic instability on the economic growth through the use of time series data and macroeconomic instability indicator in the years from 1974 to 2008 is the main objective of this study. For this purpose, a regression equation has been used based on neoclassical endogenous growth model. The results, within the framework of collective method and vector error correction model, show that economic growth in Iran has a long-term relationship with the macroeconomic instability. In other words, changes in macroeconomic instability indicators will be associated with the increase (decrease) of economic growth in the long run. Also, the obtained results show that although population growth rate is effective on the long-term economic growth, it is not influenced by the consequences of this effect. In fact, this variable is weak in comparison with other exogenous variables in the short run.
\end{abstract}

Keywords: Macroeconomic Instability, Economic Growth, Iran

JEL Classification: E00; 011; 057 


\section{Introduction}

Nowadays, this assumption has been approved that macroeconomic stability requires growth, investment and productivity in the economy, so that weak performance of economic growth is related to the macroeconomic instability. (Hausman \& Gavin, 1996)

Macroeconomic stability is fundamental basis of sustainable economic growth, because, it increases national saving and private investment and also improves exports and balance of payments with improving competitiveness.

Sustainable economic growth requires free and competitive function of prices and setting up a safe economic environment for promoting private sector investment. In this regard, macroeconomic stability can have very effective role. (Dhonte \& Kapur, 1997)

On the other hand, macroeconomic stability is required for the success of any liberation and financial reform and adjustment policies. (Turtelboom, 1991)

There are several factors that are named as potential determinant of the macroeconomic instability such as instability in inflation, incorrect fiscal policy, instability of real exchange rate and exchange relationship. The aforesaid factors are serious obstacles to the economic growth. In theoretical literature, effect of inflation is ambiguous on the growth. According to the Mandel and Tobin hypothesis, inflation has a positive effect on the growth, because, the anticipated inflation is led to the lower real interest rate and this issue is led to the change of portfolio of assets from real monetary asset to the real physical asset. (Ghura, 1995)

According to the incomplete adjustment hypothesis, inflation in the short term cannot have positive effects on the growth. But in some alternative presented theories, (Georgia 1995), higher anticipated inflation will lead remarkable resources of firms and households towards the liquidity management.

Also, with the increased cost of the capital goods, capital accumulation and consequently its real growth will be affected negatively. In addition, elasticity of investment in the developing countries is insignificant in comparison with the changes of interest and adjustment in portfolio of assets is in line with the real physical assets such as land, real estate, foreign currency, jewelries, etc.

Regarding fiscal policy, definitive judgment cannot be materialized theoretically.

There is no doubt that capital expenditures (construction and development) of the government can have significant impact on the accumulation of private capital and promotion of economic growth. The government investment can be considered as an indicator of appropriateness of basic economic and social infrastructures and contribution of the government to accumulate the capital.

Despite this, government fiscal policy in many developing countries such as Iran has also been considered as a destabilizing factor. Getting access to easy-collectable resources to meet budget deficit, poor management of macroeconomic and lack of an appropriate strategy 
of development have caused, moreover having positive effects of capital expenditures, extreme spread of harmful effects of macroeconomic instability in such a way that more doubt has been cast in positivity of the government intervention. (Khalili Araghi \& Ramezanpour, 2001)

With regard to the instability of real exchange rate, it can be said that real exchange rate increases capital accumulation in tradable goods sector due to the provision of strong price incentives and high profitability of exports on one hand and decreases capital accumulation in non-tradable goods sector due to the general hike of costs (as a result of increased general level of prices) and also increased interest rate on the other hand.

The increase of exchange rate gap and increase of foreign exchange fluctuation will cause increased risk and uncertainty, interrupting flow of investment, shortening the horizon, allocation of resources towards liquidity management, increased rent seeking, etc. in a way that these factors will decrease real growth of economy in the short term. (Cottani, Cavallo and Khan, 1990)

Standard deviation of percentage changes in the exchange relationship is another indicator which is used as an approximation of macroeconomic instability in experimental tests.

The exchange relationship is one of the most important indicators of external shocks to the economy. Harmful and adverse fluctuations in exchange relationship increases imports cost to the income ratio. Therefore, consecutive decrease in the exchange relationship can intensify current account deficit (a proportion of gross domestic product (GDP), payments balance indicator and macroeconomic stability along with harmful and adverse outcomes on the private investment. Fluctuations in world prices will not only bring about economic uncertainty, but also will affect inflation rate, real exchange rate, allocation of resources and investment perspectives. An increase in the price of the imported goods, which has much weight in the cost of living index, will have a direct impact on the consumer prices. The price downturn in the subdivision of agricultural exports will exclude the resources from that sector and will weaken investment incentive in this sector. External prices shock will cause large fluctuations in real exchange rate, details of which are of paramount importance especially for oil exporters. (Oshikoya, 1994)

Macroeconomic stability is the basis of any successful effort for the development of private sector and economic growth.

In the study of Hausman and Gavin (1996), it has been shown that economies with larger and more fluctuations (more unstable) have very unequal income distribution than other economies.

Also, comparative studies between different countries show that growth, investment and efficiency has positive correlation with macroeconomic stability. Generally speaking, results of studies indicate that macroeconomic instability is associated with the poor performance of the economic growth. 
In addition to the low economic growth rate (sometimes even negative), other aspects of macroeconomic instability impose heavy pressures on the poor. (Ames, Brown, Ddevarjan and Izquierd, 2003)

\section{Instability Theoretical Basics (Economic)}

Generally, economic instability has been the subject of few studies so that extensive and comprehensive theoretical tools cannot be found for it.

In this part, theoretical basic of economic instability is put forward and is extended as much as possible. The theoretical basic plan is very important for the economic instability, because, nature, method of measurement, causes and consequences of this phenomenon cannot be commented without possessing a reliable theoretical framework.

\subsection{Economic Perspectives on the Macroeconomic Instability}

\section{A) Traditional Perspective}

Nowadays, as far as macroeconomic is concerned, a model has been developed for the economic fluctuations, based on which, competing theories are usually compared with each other within its framework. In this model, presenting different models based on different hypotheses on the financial and monetary policies and intensity wage stickiness, and also possibility of considering different economic shocks as well as supply and demand shocks are possible. Also, in this model, a certain numerical coefficient named "Increasing Coefficient" is defined for each shock which indicates effectiveness rate of the shock on the national production. The increasing coefficient is obtained as a function of model parameters which will be called the economic structural factors. Hence, role of structure on the economic instability can be specified in the traditional model with the increasing coefficient of the shocks. The more increasing coefficient of a specific shock is found larger, the more shock will be affected on the national production. So, economic instability will be found more.

In other words, great vulnerability of the economy for the given shock can be measured with the increasing coefficient of that shock. For example, in a model of the demand side, the government expenditures are extracted as follows: (Doronbush \& Fischer, 1999)

$$
\text { (1) } \frac{\Delta \mathrm{y}_{0}}{\Delta \overline{\mathrm{G}}}=\frac{\mathrm{h} \bar{\alpha}}{\mathrm{h}+\mathrm{bk} \bar{\alpha}}
$$

Wherein,

"b" is marginal propensity to invest, " $h$ " and " $k$ " are the sensitivity of money demand to the interest rates and income respectively.

“ $\bar{\alpha} "$ is defined as follows: 


$$
\bar{\alpha}=\frac{1}{1-\mathrm{c}(1-\mathrm{t})}
$$

Wherein,

"c" is marginal propensity to consume and " $\mathrm{t}$ " is income tax rate.

Equation (1) shows that a certain amount of confusion in the government expenditure will create how much turmoil in the national income or level of economic activities. As it is observed, its amount is determined by the exogenous variables like money demand equation coefficients, capital investment, and/or consumption function, which show structure of behavior of individuals within the economy, and/or policy-setting variables like income tax rate. Thus, some structural features of economy determine the range of instability in the economic activities caused by the emergence of a disturbance and/or certain shock.

Thereupon, structure of economy plays an important role in determination of vulnerability degree of an economy against shocks. The variables like tax rate, which is controlled by the government, are effective on the increasing coefficient. Increase in income tax rates will decrease the increasing coefficient and will led to the reduction of economic vulnerability against shocks.

Unemployment compensation benefits are of the other variables which are not entered the abovementioned simple model but they are allowed to operate as an automatic stabilizer. When worker are unemployed and reduce their consumption, this reduction in consumption demand will have increasing impact on the national production. The outcomes of increasing coefficients will be more limited when workers receive unemployment compensation benefits and when their disposable income is reduced by less than the lost gain. Although stabilizers have favorable consequences, they cannot be used comprehensively without affecting general performance of the economy. The increasing coefficient may be reduced to a single digit through the tax increase as much as $100 \%$.

Apparently, this affair bears stabilizing effects for the economy, but there is not any motivation to continue work in $100 \%$ tax rate and consequently, gross domestic product (GDP) will be reduced.

So, there are limitations in the field of using automatic stabilizers. (Doronbush \& Fisher, 1999)

Except economic structure and also automatic stabilizers, the government, as an economic institution, plays an important role in the economic stability.

With implementing different policies especially economic stabilization policies, the government tries to confront with the economic fluctuations and affects the economic instability as well. But the way of implementation of these policies, which is more dependent on the structural and institutional features of the government, is of paramount importance as much as selection of an accurate policy. If there are some structural barriers for the accurate selection of the policies, identification of accurate policy and also precise implementation of 
that policy will be impossible. The policies are in three stages so that accurate and timely implementation of each stage will have an important role in their effectiveness. These three stages include: identification stage, decision-making stage and action stage.

At first, the need to adopt a certain policy (e.g. anti-recession policy or policy to reduce inflation) should be recognized. This stage is dependent on the existence of accurate and timely information and is considered as the most sensitive stages of a policy, because, if need to a policy is not recognized accurately, the next stages, even in the best conditions, will not produce favorable result.

The evaluation of this stage is checked with two indicators. The first indicator determines accuracy of the information and the second indicator shows appropriate time to access information. Inaccuracy of information wills likely increase adoption of incorrect policies and this increase is usually led to the worsening economic conditions and more instability. In addition, execution of a proper policy in a wrong time can be another factor for instability. For example, if implementation of an anti-recession policy is taken after with more delay, so that recession stage is terminated and economy is entered a lucrative period, implementation of this policy at this time will increase inflation tremendously and will extent the inflation period excessively. Therefore, implementation of this policy will be associated with its increase instead of reducing instability.

This affair, i.e. identification of a policy accurately and timely, is so important that a group of economists, like monetarists, are of the opinion that the government should never be executor of monetary policies with the objective of economic stability, because, due to the impossibility of accurate and on-time recognition of policies, implementing them will lead to its instability instead of economic stability.

Decision making is put forward at the next stage. For example, when the government identifies necessity of adopting an anti-recession policy, it should decide how to implement this policy. For example, government may face high budget deficit and identify that an anti-recession policy should be adopted, under such circumstances, the government decides to increase its expenses.

Thereupon, if rate of its expenses is increased and if budget deficit rate is increased, forcing the government to receive foreign loans and/or publishing money, under such circumstances, the government policy will led to the increased inflation and consequently, macroeconomic instability.

Therefore, accurate and on-time decision is of paramount importance. The policy action stage is put forward in the final stage.

In this stage, recognition and making decision is carried out and is acted for the practicality of policy. For example, the government decides to implement policy of increasing public expenses, now the increase rate and time in action stage may differ from appropriate time and rate, under such circumstances, improper implementation of policy will lead to the increased macroeconomic instability. 
Hence, proper and timely implementation of three-category policy setting stages plays a leading role in reducing instability.

B) Institutionalists View

In institutionalists view, special attention is paid to the role of institutions (as the economic structure) in behavior of economic agents.

Douglass North (1998) defines the institutions as follows: "Institutions are the rules in the society. In other words, institutions are the constraints imposed by the human being which form human interaction with one another."

Some institutional economists have discussed on studying the role of democratic institutions in macroeconomic instability and all of them have emphasized that democratic institutions can reduce instability.

In other words, macroeconomic instability in democratic governments is less than the nondemocratic governments. According to them:

1. The countries with democratic government avoid resorting to the divisive policies and settle their social conflicts and disputes, which led to the macroeconomic instability, with compromise. Undoubtedly, more consultation in policy, social cooperation and reduction of negative effects of subassemblies are of the salient features of democratic governments. In a democratic government, all social groups are allowed to offer their views peacefully and amicably in political decisions. The said issue will prevent outbreak of social disputes of subcultures.

Direct function of these three features is the materialization of the policies that are accepted by all walks of life and even, opposition of some individuals are put forward peacefully as well. Reduction of policies' instability and also decrease of social crises are of the outcome of this peaceful environment which is usually associated with the negative economic consequences especially macroeconomic instability.

2. Democratic governments have less macroeconomic instability because; leaders of democratic governments are limited by the risk-averse citizens in their choices. Therefore, possibility of adoption of risky policies, which is led to more instability, is reduced. So, in these governments, more macroeconomic stability will be established. Existence of risk-averse individuals against risk-gathering policymakers is the basic assumption of this theory. Regarding the policies followed by the risk, when policymakers know that people's expectations (who select them) will play a leading role in their political futures, they embark on implementing policies which are more consistent with the people's expectations. So, the policies that are implemented in these systems (democratic) will enjoy less risk and consequently, less macroeconomic instability will be followed up.

3. The democratic governments are known due to the multiplicity of the democratic 
institutions. If there are more institutions in a society, it is meant that more democracy is disseminated in that society. Now, in such society, possibility of implementation of extremist policies, which is associated with the economic instability, is reduced, because, increase of democratic institutions, which can play an active role in political decision makings, can identify blunders of extreme policies that mar its production and stability and hinder execution of these policies. But in the governments with fewer institutions, the possibility of adoption of wrong and extreme decisions, which will lead to the macroeconomic instability, is increased. (North, 1998)

\section{C) Development Perspective}

In development perspective which is presented by some of development economists for certain group of countries (Barati, 2008), instability or vulnerability of these countries have been studied from a structural perspective. The studies made in this regard have led to the presentation of a parameter entitled "Economic Vulnerability", based on which, cause of vulnerability of these economies have been studied. The idea of construction of vulnerability indicators in the international communities was developed for the first time during the discussions related to the losses which developing Island countries faced them.

\section{Methodology}

\subsection{Data Sources}

The data used in this study has been extracted from the published accounts and time series data of the Central Bank and Statistical Yearbook of Statistic Center of Iran (SCI) in the years from 1974 to 2008 .

\subsection{Model Stipulations}

In this study, a regression model is extracted according to Mankiw (1992), Romer (1992), Knight (1993) and Hadjimichael et al., (1994) and from one specific production function to study relationship of macroeconomic instability and economic growth.

In the beginning, a production function of Cobb -Douglass type is assumed with the following structure:

$$
\text { 2. } Y=A_{0}\left(A_{K} K\right)^{\alpha}\left(A_{H} H\right)^{\beta}\left(A_{L} L\right)^{1-\alpha-\beta}
$$

Wherein,

"Y" is real product, " $\mathrm{L}$ " is workforce, " $\mathrm{K}, \mathrm{H}$ " is balance of human and physical capital, " $\mathrm{A}_{0}$ " is general indicator of technology and efficiency in economy, " $=A_{L}, A_{H}, A_{K}$ " is the increased technology of human, workforce and physical capital with the "A" definition as follows: 


$$
\text { 3. } A=A_{L}\left(A_{0} A_{K}^{\alpha} A_{H}^{\beta}\right)^{\frac{1}{1-\alpha-\beta}}
$$

The equation (2) can be written as follows:

$$
\text { 4. } Y=K^{\alpha} H^{\beta}(A L)^{1-\alpha-\beta}
$$

Wherein,

"A" shows the general level of technology and efficiency. In this formula, "A" can be interpreted as a parameter which merely reflects increasing technology of work.

Barro \& Sala - i -Martine (2000) show that progress of technology should increase workforce in order to have a sustainable situation. It is assumed that accumulation, labor force growth and technology should be according to the following functions:

$$
\begin{aligned}
& \text { 5. } L=L_{0} e^{n t} \\
& \text { 6. } A=A_{0} e^{(g t+x \theta)}
\end{aligned}
$$

Wherein,

" $n$ " represents exogenous rate of labor force growth

" $\mathrm{t}$ " represents a time indicator

"g" represents technical progress exogenous

" $\mathrm{X}$ " is a vector of policy variables and other factors affecting technology and efficiency level in economy,

$=\theta_{\text {Represents a vector of coefficients related to this policy variables and other effective }}$ factors

If fraction of income, which is allocated for the human and physical investment, is shown with $\mathrm{S}_{\mathrm{k}}$ and $\mathrm{S}_{\mathrm{h}}$, under such circumstances, accumulation of human and physical capital (assuming that each of two types of capital balances are depreciated with the equal rate $(\delta)$ for the simplicity) will be according to the following functions:

$$
\begin{aligned}
& \text { 7. } \frac{d K}{d t}=S_{k} Y-\delta K \\
& \text { 8. } \frac{d H}{d t}=S_{h} Y-\delta H
\end{aligned}
$$


With explaining inventory of physical and human capital and real product / effective force unit, i.e.:

$$
k=\frac{K}{A \cdot L}, h=\frac{H}{A \cdot L}, y=\frac{Y}{A \cdot L}
$$

The production function and physical and human capital accumulation functions are rewritten according to the per capita amounts of effective labor force unit as follows:

$$
\text { 9. } y=k^{\alpha} \cdot h^{\beta}
$$

$$
\begin{aligned}
& \text { 10. } \frac{d k}{d t}=S_{k} y-(n+g+\delta) k \\
& \text { 11. } \frac{d h}{d t}=S_{h} y-(n+g+\delta) h
\end{aligned}
$$

In stable condition, physical and human capital level will remain constant per effective labor force unit. So, equations (10) and (11) are considered equal to "zero" and are solved. With solving these equations, the below values (balanced values of effective physical and human capital per capita) are obtained:

$$
\begin{aligned}
& k^{*}=\left[\frac{S_{k}^{1-\beta} S_{h}^{\beta}}{n+g+\delta}\right]^{\frac{1}{1-\alpha-\beta}} \\
& \text { 12. } h^{*}=\left[\frac{S_{k}^{\alpha} S_{h}^{1-\alpha}}{n+g+\delta}\right]^{\frac{1}{1-\alpha-\beta}} \\
& \text { 13. }
\end{aligned}
$$

By putting the above equations in Equation (9) and taking natural logarithm, effective labor force per capita product in a stable condition is achieved:

$$
\text { 14. } \text { Lny }^{*}=-\left[\frac{\gamma}{1-\gamma}\right] \ln (n+g+\delta)+\left[\frac{\alpha}{1-\gamma}\right] \ln S_{k}+\left[\frac{\beta}{1-\gamma}\right] \ln S_{h}
$$

And $\gamma=(\alpha+\beta)$ 
With taking natural logarithm from $y=\frac{Y}{A \cdot L}$ and using Equation (6) instead of "A", an experimental version of Equation (14) is obtained as follows:

$$
\begin{gathered}
\ln y=\ln \left(\frac{Y}{L}\right)-\ln A=\ln \left(\frac{Y}{L}\right)-\ln A_{0} e^{(g t+x \theta)} \\
\text { 15. } \ln \left(\frac{Y}{L}\right)=\ln y+\ln A_{0}+g t+x \theta
\end{gathered}
$$

By putting this equation in (14), we will have:

16.

$$
\operatorname{Ln}\left[\frac{Y}{L}\right]=\ln A_{0}+g t+x \theta-\left[\frac{\gamma}{1-\gamma}\right] \ln (n+g+\delta)+\left[\frac{\alpha}{1-\gamma}\right] \ln S_{k}+\left[\frac{\beta}{1-\gamma}\right] \ln S_{h}
$$

From Equation (16), a growth regression equation can be extracted for each economy with considering its economic condition. An experimental version of this equation is used for the Iranian economy in the present study, as follows:

$$
\text { 17. } P C R Y G_{t}=\eta_{1}\left(P G_{t}+g+\delta\right)+\eta_{2} P I Y_{t}+\eta_{3} G I Y_{t}+\eta_{4} S S E R_{t}+\theta_{1} M I I_{t}+\varepsilon_{t}
$$

And then,

$$
\text { 18. } P C R Y G_{t}=\eta_{1} E L G_{t}+\eta_{2} P I Y_{t}+\eta_{3} G I Y_{t}+\eta_{4} S S E R_{t}+\theta_{1} M I I_{t}+\varepsilon_{t}
$$

Wherein,

PCRYG : Which represents per capita real gross domestic production growth rate.

ELG : Which represents population growth rate (Employee Population).

$P I Y$ : Which represents private investment yield to GDP.

GIY : Which represents governmental investment yield to GDP.

SSER: Which represents registering in elementary, guidance and secondary level as a parameter of human capital development.

MII : Which represents as Macroeconomic Instability Index.

\section{Variable Representing Macroeconomic Instability}

A macroeconomic instability criterion is proposed to obtain a general picture of macroeconomic and policies stability situation which is a combination of inflation, budget deficit, real exchange rate fluctuations, and changes in the exchange relationship. Need to use 
different factors simultaneously have been emphasized by Fisher (1993), and Sahay and Goyal (2006) in order to determine macroeconomic situation. A combined index is appropriate for this purpose, because, each variable has only partial information separately. For example, inflation is a good index of monetary and financial status but it may be affected by the prices control. When inflation price controls are kept low, uncertainty and lack of confidence in fiscal policies imposes pressure on the exchange rate. The exchange rate pressures may not be revealed under a constant exchange rate regime, but policymakers try to stabilize foreign currency within the framework of changes in the international reserves.

Usually, the inflation rate is used as a substitution criterion of macroeconomic instability. In an article entitled "Sources of Growth and Total Productivity Behavior of Production Factors in Chile", Fuentes, Larraine and Schmidt-Hebbel (2006) have used inflation rate as an index for the macroeconomic instability.

But despite this, Macroeconomic Instability Index (MII) is a relatively more comprehensive criterion of the macroeconomic instability.

Hence, an increase in macroeconomic instability index (MII) is meant an increase in one or more indexes of macroeconomic instability, such as increase in inflation rate; change in exchange rate, public deficit ratio to gross domestic product (GDP) and foreign debt ratio to gross domestic product (GDP). (Ismihan, 2003)

Usually, Macroeconomic Instability Index (MII) is calculated through the use of methodology of the United Nations Development Program (UNDP) in calculation of Human Development Index (HDI) and based on four macroeconomic instability indexes such as inflation rate, changes in exchange rate (variability of exchange rate), public deficit ratio to the gross domestic product (GDP) and foreign debt ratio to the gross domestic product (GDP).

Since the mentioned indexes are not identical from measurement range and units (for example, having different maximum and minimum), it seems that their total and average is not logical in order to construct a combined index. Fortunately, HDI Methodology will solve this problem. For this purpose, MII is built in two stages. In the first stage, the mentioned four macroeconomic instability indexes are built based on the following relation:

$$
I_{t}=\frac{\left(x_{t}-x_{\min }\right)}{\left(x_{\max }-x_{\min }\right)}
$$

Wherein,

"I "represents " $\mathrm{X}$ " variable value index. For example, in macroeconomic instability index (MII) of " $X$ " in " $t$ " year, " $X_{t}$ " represents the real value of " $X$ " in " $t$ " year and $X_{\min }\left(X_{\max }\right.$ represents maximum and minimum value of index " $X$ " in whole studied period. It should be noted that all sub-indices have a common range. For example, they are limited to 0 and 1 . In the second stage, Macroeconomic Instability Index (MII) is obtained based on the four simple averages as achieved in above. So, MII is also limited to 0 and 1. (Ismihan, 2003) 
In another study made by Jaramillo \& Sancak (2007), macroeconomic instability index (MII) has been defined as total weighted rate of inflation, exchange rate fluctuation minus accumulated reserves as a percentage of monetary base at the start of each period) and minus financial balance as a percentage of gross domestic product (GDP). Weight of each variable is reverse to the standard deviation (SD). In other words, each variable is weighted inversely to the SD.

In this index, the inflation rate has been defined as annual change percentage of consumer price index, exchange rate fluctuations as percent change in foreign exchange rate, accumulation of international reserve as annual change in international reserves as a percentage monetary base at the start of each period and financial balance as government financial balance ratio to the gross domestic product (GDP). (Jaramillo \& Sancak, 2007)

$$
M I I_{t}=\frac{\operatorname{Ln}\left(\frac{C P I_{t}}{C P I_{t-1}}\right)}{\delta_{c p i}}+\frac{\operatorname{Ln}\left(\frac{e r}{e r_{t-1}}\right)}{\delta_{e r}}-\frac{\operatorname{Ln}\left(\frac{\text { res }_{t}-r e s_{t-1}}{b m_{t-1}}\right)}{\delta_{\text {res }}}-\frac{\operatorname{Ln}\left(\frac{f b a l_{t}}{g d p_{t}}\right)}{\delta_{\text {fbal }}}
$$

In the present study, with combing each two methods, Macroeconomic Instability Index (MII) is built and extracted in Iran. The used variables include inflation rate (inf), change in real exchange rate (ex)(Note 1), budget deficit rate to the gross domestic product (bd) and change in exchange relationship (tot)(Note 2)

This index has been defined as total weight of inflation rate, real exchange rate fluctuations, and change in the budget deficit and fluctuations in the exchange relationship. It should be noted that weight of each variable is varied equivalent to its standard deviation (SD).

$M I I_{t}=\alpha\left(\frac{\inf _{t}-\operatorname{mininf}}{\max \inf -\operatorname{mininf}}\right)+\beta\left(\frac{e x_{t}-\min e x}{\max e x-\min e x}\right)+\gamma\left(\frac{b d_{t}-\min b d}{\max b d-\min b d}\right)+\varphi\left(\frac{t_{t}-\min t o t}{\max t o t-\min t o t}\right)$

In this relation, weight of index components (prices instability index, exchange instability index, budget deficit instability index, and instability of exchange relationship) are selected so that their sum is equal to one. In other words, the following relation should be obtained: $\alpha+\beta+\gamma+\varphi=1$

More value of this index is meant more instability. In diagram (1), conflict between economic growth and macroeconomic instability has been depicted. As it is observed, economic growth has been affected and decreased in the years which macroeconomic instability has been increased.

Studying correlation status between two variables indicates severe negative correlation $(-0.6)$. 


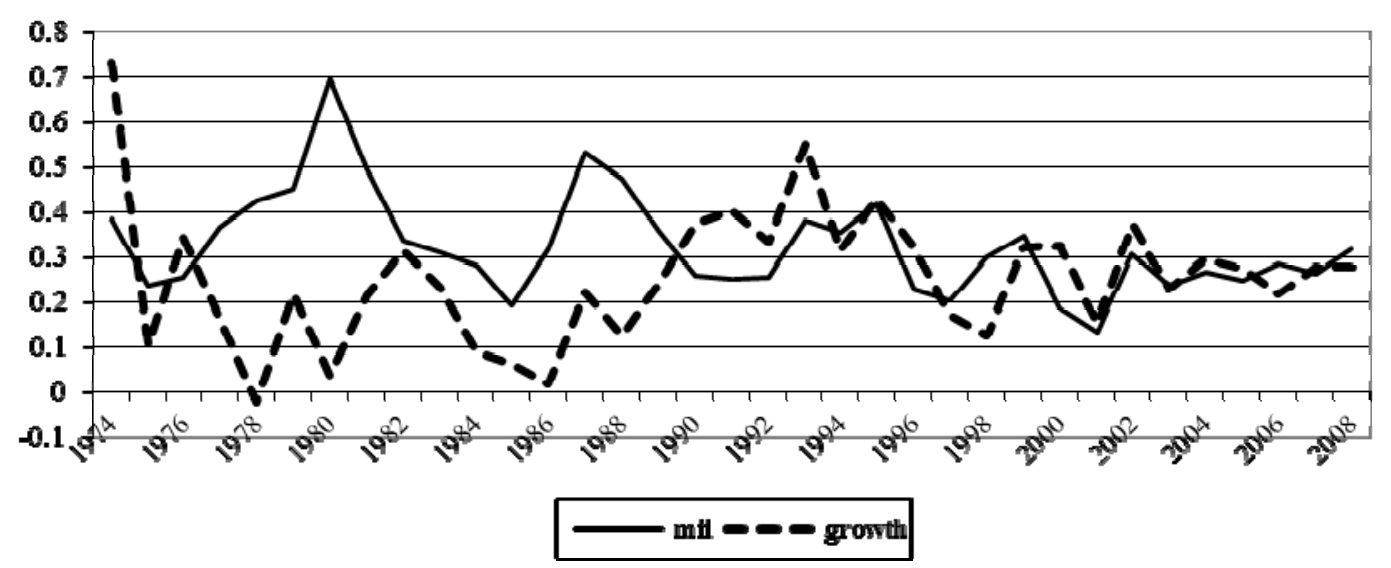

Diagram (1): Macroeconomic Instability Index and Economic Growth of Iran during 1974-2008

\section{Discussion and Estimation}

\subsection{Estimation of Long-Term Relationship and Extraction of Collective Vectors Based on Johansen -Juselius Method}

Before entering the discussion on the determination of co-integration vector, it should be noted that co-integration discussion is posed only to the variables which are unstable and should be of the same order. For this purpose, all the variables are first tested by the Augmented Dickey -Fuller statistics. Of course, it is not necessary that all model variables together are of the same order (unless $\mathrm{K}$ is equal to 2 i.e. $\mathrm{K}=2$ ) in order to prevent occurrence of spurious regression. It is possible that when model variables are a set of variables of I (0), I (1) and I (2), their linear combination is I (0) and consequently, co-integration is obtained, because, linear combination of I(2) variables may be co-integrated and form I(1) variable. Therefore, linear combination of this variable has been modeled as I (0) with other I (1) variables in order to guarantee co-integration relationship. However, existence of variables I (2) between model variables do not negate possibility of obtaining a steady relationship. Despite this, Johansen Method, which has been designed for convergent variables from first grade, cannot present necessary steady vectors during existence of I (2) variables. Thereupon, when there is variables I (2) between model variables, if Johansen ordinary method is used, I (2) variables should be converted into I(1) through the use of difference equation. (Nofresti, 1999)

In Johansen -Juselius Method to obtain a long-term relationship between variables, existence of co-integration and number of co-integration relationship are first specified through the use of two statistics of Maximum Eigen Value Test $(\lambda \max )$ and Trace Test ( $\lambda$ trace).

In the Maximum Eigen Value Test, the null hypothesis i.e. "lack of existence of a co-integration relationship against existence of a co-integration relationship" and "existence of one or less than one co-integration relationship against two co-integration relationship" etc. are tested respectively. In Trace Test, hypothesis of "lack of existence of co-integration 
relationship against existence of one or more than a co-integration relationship" and "existence of one or less than a co-integration relationship against existence of two or more con-integration relationship", etc. are tested respectively.

If test statistics, related to these variables, exceeds critical values in $3 \% 1$ level, null hypothesis is rejected. Accordingly, the number if collective vectors are obtained.

In the next stage, the operation of normalizing on the vectors is carried out based on one of the arbitrary variables. Significance of each coefficient is studied through the use of Maximum Likelihood Ratio (ML).

\subsubsection{Studying Reliability of Variables (The Augmented Dickey-Fuller (ADF) Unit Root Test)}

Given that time series are usually unstable in macroeconomic studies and their instabilities bring about outbreak of spurious regression in experimental studies, hence, reliability of variables have been tested through the use of Augmented Dickey-Fuller (ADF) Unit Root Test. Summary of Augmented Dickey-Fuller (ADF) Unit Root Test results have been shown in Table 1 as follows:

Table 1: Summary of Augmented Dickey-Fuller (ADF) Unit Root Test Results in 1\% Level

\begin{tabular}{llllll}
\hline No. & Time Series & Variable & $\begin{array}{l}\text { ADF } \\
\text { Statistics Value }\end{array}$ & $\begin{array}{l}\text { Test } \\
\text { (ADF) }\end{array}$ & Value \\
\hline 1 & GDP growth rate & PCRYG & -3.71 & -3.64 \\
2 & Employee population growth rate & ELG & -3.18 & -3.64 \\
3 & Investment ratio of private sector to & & & -3.64 \\
& GDP & PIY & -3.52 & -3.64 \\
4 & Investment ratio of public sector to GDP & GIY & -2.61 & -3.64 \\
5 & Human capital development index & SSER & -1.44 & -3.64 \\
6 & Macroeconomic instability index & MII & -3.5 & \\
\hline
\end{tabular}

As it is observed in Table 1, all variables, except per capita real GDP growth rate, are unstable in $1 \%$ critical value and level (for rejection of null hypothesis). For this purpose, reliability of the mentioned variables has been studied in first-order difference and the same critical value, results of which have been shown in Table 2 .

Table 2: Summary of Results of Augmented Dickey-Fuller (ADF) Unit Root Test in First-Order Difference (in 1\% Level)

\begin{tabular}{llllll}
\hline No. & Time Series & Variable & ADF Test & $\begin{array}{l}\text { Critical } \\
\text { Value }\end{array}$ & $\begin{array}{l}\text { Collective } \\
\text { Degree }\end{array}$ \\
\hline 1 & GDP growth rate & PCRYG & - & - & - \\
2 & Employee population growth rate & ELG & -4.12 & -3.64 & $\mathrm{I}(1)$ \\
3 & Investment ratio of private sector to GDP & PIY & -5.42 & -3.64 & $\mathrm{I}(1)$ \\
4 & Investment ratio of public sector to GDP & GIY & -4.72 & -3.64 & $\mathrm{I}(1)$ \\
5 & Human capital development index & SSER & -4.45 & -3.64 & $\mathrm{I}(1)$ \\
6 & Macroeconomic instability index & MII & -5.33 & -3.64 & $\mathrm{I}(1)$ \\
\hline
\end{tabular}




\section{Macrothink}

According to Table 2, all variables have been turned stable in $1 \%$ significant level and in first-order difference.

\subsubsection{Determine Optimal Number of Breaks in VAR Model}

To determine optimal number of breaks (considering limitations in the number of variables and data for Johansen -Juselius Method), the model was tested with three breaks, based on which, number 1 optimal break is selected based on AIC (Akaic Criteria) and Schwartz Criteria (SBC).

\subsubsection{Determine Collective Vectors between Variables}

The results of estimation of collective vector between the mentioned variables and number of collective vectors have been presented in Table (3) and (4). This table has been comprised of three parts. In the first two parts, effect statistics and maximum special values have been calculated for determining the number of collective vectors. According to the statistics reported in these two parts, maximum special value statistics and effect statistics in Tables (3) and (4) confirm long-term relationship between the mentioned variables. Monte Carlo studies have shown that when statements of residuals of equations enjoy excessive skewness or kurtosis, the effect test is more robust than the maximum value test. (Nofersti, 1999)

So, existence of a collective vector between real GDP growth rate, population growth rate, private sector investment to gross domestic product (GDP), public sector investment ratio to GDP, human capital development index, and macroeconomic instability index are accepted in $1 \%$ confidence level and by virtue of results of effect statistics.

Table 3: Results of Vector Estimation and No. of Collective-Effect Statistics Vectors

\begin{tabular}{ccccc}
\hline $\begin{array}{c}\text { Hypothesized } \\
\text { No. of CE(s) }\end{array}$ & Eigenvalue & $\begin{array}{c}\text { Trace } \\
\text { Statistic }\end{array}$ & $\begin{array}{c}\text { 5 Percent } \\
\text { Critical Value }\end{array}$ & $\begin{array}{c}1 \text { Percent } \\
\text { Critical Value }\end{array}$ \\
\hline None ** & 0.823382 & 117.5511 & 94.15 & 103.18 \\
At most 1 & 0.531248 & 60.33691 & 68.52 & 76.07 \\
At most 2 & 0.433499 & 35.33346 & 47.21 & 54.46 \\
At most 3 & 0.297127 & 16.58036 & 29.68 & 35.65 \\
At most 4 & 0.086415 & 4.945251 & 15.41 & 20.04 \\
At most 5 & 0.057743 & 1.962743 & 3.76 & 6.65 \\
& & & & \\
\hline
\end{tabular}

${ }^{*}(*)$ denotes rejection of the hypothesis at the $5 \%(1 \%)$ level

Trace test indicates 1 cointegrating equation(s) at both 5\% and 1\% levels 


\section{Macrothink}

Research in Applied Economics

ISSN 1948-5433

2012, Vol. 4, No. 3

Table 4: Results of Vector Estimation and No. of Collective-Maximum Special Value Statistics Vectors

\begin{tabular}{ccccc}
\hline $\begin{array}{c}\text { Hypothesized } \\
\text { No. of CE(s) }\end{array}$ & Eigenvalue & $\begin{array}{c}\text { Max-Eigen } \\
\text { Statistic }\end{array}$ & $\begin{array}{c}\text { 5 Percent } \\
\text { Critical Value }\end{array}$ & $\begin{array}{c}1 \text { Percent } \\
\text { Critical Value }\end{array}$ \\
\hline None ** & 0.823382 & 57.21421 & 39.37 & 45.10 \\
At most 1 & 0.531248 & 25.00345 & 33.46 & 38.77 \\
At most 2 & 0.433499 & 18.75310 & 27.07 & 32.24 \\
At most 3 & 0.297127 & 11.63511 & 20.97 & 25.52 \\
At most 4 & 0.086415 & 2.982508 & 14.07 & 18.63 \\
At most 5 & 0.057743 & 1.962743 & 3.76 & 6.65 \\
& & & &
\end{tabular}

${ }^{*}(* *)$ denotes rejection of the hypothesis at the $5 \%(1 \%)$ level

Max-eigenvalue test indicates 1 cointegrating equation(s) at both $5 \%$ and $1 \%$ levels

In the fifth part, results of estimation and normalized value of collective vector has been reported.

Table 5: Results of Normalization

\begin{tabular}{|c|c|c|c|c|c|}
\hline \multicolumn{2}{|c|}{1 Cointegrating Equation(s): } & Log likelihood & 442.6421 & & \\
\hline \multicolumn{6}{|c|}{ Normalized cointegrating coefficients (std.err. in parentheses) } \\
\hline PCRYG & MII & GIY & $E L G$ & $P I Y$ & SSER \\
\hline \multirow[t]{2}{*}{1.000000} & 0.993444 & -1.207776 & 8.400123 & -2.525503 & -0.762745 \\
\hline & (0.13879) & $(0.22233)$ & (2.23669) & (0.41041) & $(0.25300)$ \\
\hline
\end{tabular}



This long-term relationship has been reiterated according to the following relation:

$$
P C R Y G=-0.99 \times M I I+1.2 \times G I Y-8.4 \times E L G+2.52 \times P I Y+0.76 \times S S E R
$$


According to this statement, a reverse and remarkable relationship can be observed between macroeconomic instability index and economic growth rate. In other words, changes in macroeconomic instability indicators will be associated with the increase (decrease) of economic growth in the long run. On the other hand, increase in public and private sector investment ratio to GDP and human capital development index has positive effect on the economic growth while population growth rate (active) has negative effect on the economic growth. Also, estimated adjustment coefficients show that economic growth rate is adjusted to its disequilibrium with $5 \%$ coefficient. In the same direction, variables of macroeconomic instability index, public sector investment ratio to the gross domestic product (GDP), population growth rate, private sector investment ratio to the gross domestic product and human capital development index are adjusted with $6 \%, 0.05 \%, 0.009 \%, 18 \%$ and $14 \%$ respectively.

\subsubsection{Variance Analysis and Stimulation Response Functions}

According to the results of estimation of vector auto-regression model between variables, two other analyses can be conducted to study way of relationship between variables. These two analyses include variance analysis and impulse response functions.

The variance analysis, which its results have been mentioned in Table 6 for the economic growth, shows that in the next 10 periods, each of variables explain some percent of predicted error of the economic growth rate. The results of this Table show that firstly, with the increased time, the predicted error is increased and secondly, in the next ten periods after the economic growth, which has the highest share in explaining the predicted error, the public sector investment ratio to GDP, population growth, macroeconomic instability index, private sector investment ratio to DGP and human capital development index are placed in the next ranks. In the first period, $100 \%$ of changes in the economic growth are related to the variable which has been decreased to $89.6 \%$ in the second period and $98 \%$ of which belongs to the macroeconomic instability index (MII).

The effectiveness rate of macroeconomic instability index (MII) is added gradually as of the third period on.

Table (6): Results of Variance Analysis of Predicted Economic Growth Error

\begin{tabular}{cccccccc}
\hline Period & S.E. & PCRYG & MII & GIY & ELG & PIY & SSER \\
\hline 1 & 0.062846 & 100.0000 & 0.000000 & 0.000000 & 0.000000 & 0.000000 & 0.000000 \\
2 & 0.072920 & 89.60608 & 0.989162 & 7.917235 & 0.539185 & 0.948046 & 0.000288 \\
3 & 0.079657 & 75.49931 & 2.584148 & 16.34040 & 3.664721 & 1.900192 & 0.011227 \\
4 & 0.084518 & 67.48958 & 3.571402 & 18.45461 & 8.391181 & 2.063735 & 0.029493 \\
5 & 0.086800 & 64.41384 & 3.790240 & 17.71981 & 12.08588 & 1.958458 & 0.031775 \\
6 & 0.087840 & 62.90151 & 3.709722 & 17.80118 & 13.49042 & 2.060305 & 0.036863 \\
7 & 0.088867 & 61.74353 & 3.706793 & 18.80129 & 13.37475 & 2.297623 & 0.076007 \\
8 & 0.089834 & 61.05983 & 3.800863 & 19.43411 & 13.12939 & 2.435096 & 0.140718 \\
9 & 0.090368 & 60.81336 & 3.871488 & 19.45906 & 13.20972 & 2.449166 & 0.197200 \\
10 & 0.090539 & 60.70432 & 3.883892 & 19.38605 & 13.35890 & 2.440034 & 0.226808 \\
\hline
\end{tabular}


Finally, Impulse Response Functions are studied in this part. Like predicted error analysis, Impulse Response Functions is the average stimulation show of VAR or VECM model.

These functions show dynamic behavior of model variables on each of variables during the time length at the time of single impulse.

The mentioned impulses are usually selected based on a unit size increase in standard deviation of the structural error (innovation) of each Structural Vector Auto Regressive equations related to each variable. Therefore, it is called a momentum or single impulse. The origin of coordinates or start point of response variable movement is the values related to the stable situation of the device (without presence of momentum). Through the use of impulse response functions, dynamicity of the device is specified to the single impulse as imposed by each variables of the device. Since impulse response functions are sensitive to the positioning of variables, impulse response functions are used. (Pesaran and Shin, 1998)

The results of stimulation response function have been shown in Table 7.

Table 7: Results of Stimulation Response Function Analysis

\begin{tabular}{rcccccc}
\hline Period & PCRYG & MII & GIY & ELG & PIY & SSER \\
\hline 1 & 0.062846 & 0.000000 & 0.000000 & 0.000000 & 0.000000 & 0.000000 \\
2 & 0.028549 & -0.007252 & -0.020518 & 0.005354 & -0.007100 & 0.000124 \\
3 & 0.005097 & -0.010553 & -0.024817 & 0.014278 & -0.008376 & -0.000835 \\
4 & -0.005507 & -0.009547 & -0.016776 & 0.019154 & -0.005181 & -0.001181 \\
5 & -0.005669 & -0.005518 & -0.004098 & 0.017640 & -0.000370 & -0.000536 \\
6 & -0.000542 & -0.000819 & 0.006202 & 0.011416 & 0.003379 & 0.000671 \\
7 & 0.004760 & 0.002549 & 0.010549 & 0.003916 & 0.004741 & 0.001777 \\
8 & 0.007182 & 0.003742 & 0.009142 & -0.001823 & 0.003882 & 0.002314 \\
9 & 0.006213 & 0.003070 & 0.004553 & -0.004380 & 0.001868 & 0.002179 \\
10 & 0.003144 & 0.001488 & -0.000196 & -0.004039 & $-9.76 \mathrm{E}-05$ & 0.001577 \\
\hline
\end{tabular}

The Diagram (2) shows the effect of momentum or impulse on the variables of the device as much as a standard deviation to the macroeconomic instability. As it is observed, following the mentioned momentum, per capita real GDP variable is decreased as much as $6 \%$ in the first four periods. In the same direction, per capita real GDP variable is found negative up to the sixth period and then is turned positive and is found balance up to the tenth period. 

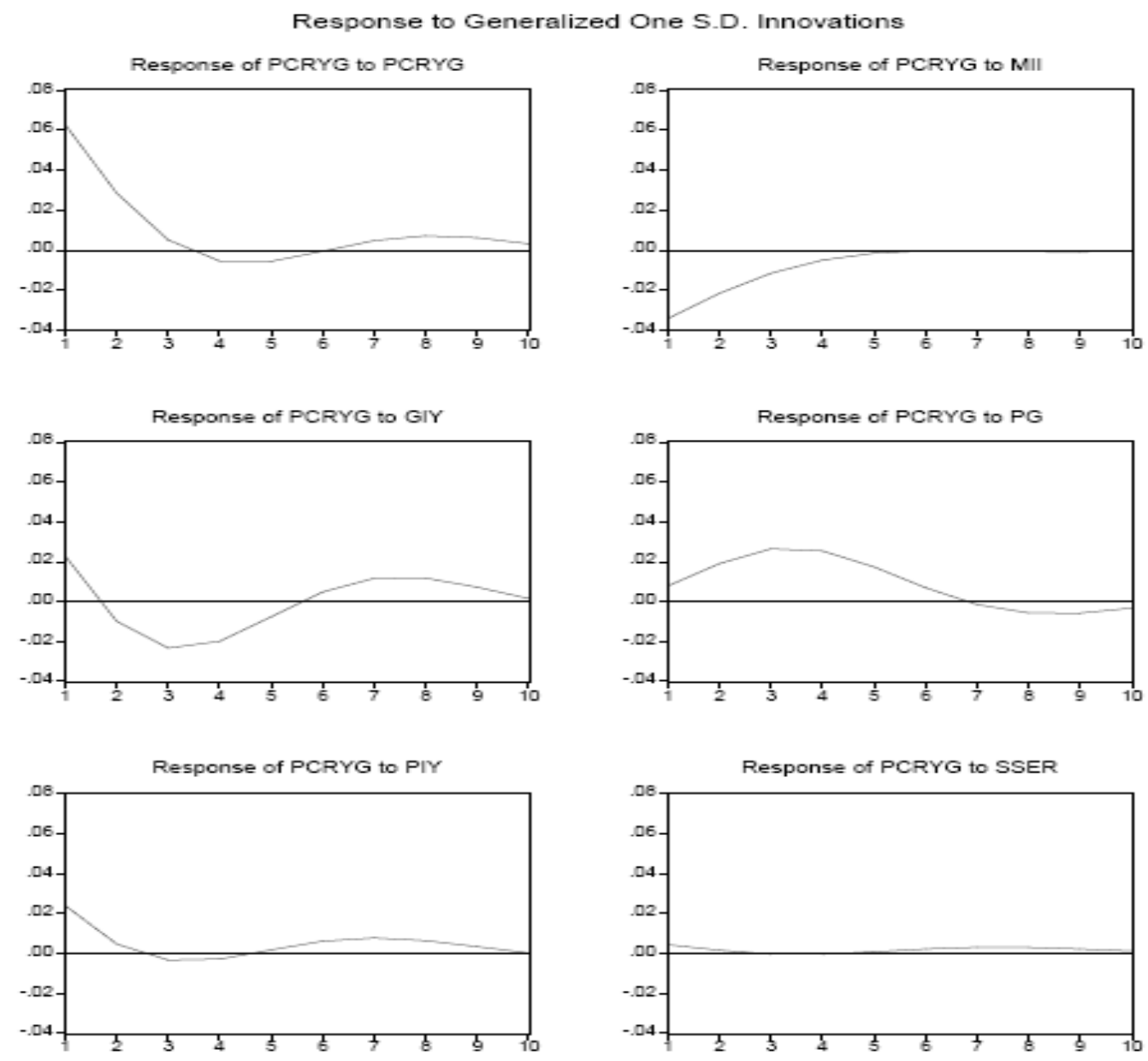

Diagram (2): Economic Growth Stimulation Response Functions to the Changes in Other Variables

\section{Summary and Conclusion}

The present study has studied effect of macroeconomic instability on the economic growth in Iran. The used data has been extracted from the accounts published by the Central Bank of Iran (CBI) and Statistical Yearbook of the Statistic Center of Iran (SCI) in the years from 1974-2008.

The results, according to Johansen -Juselius Method, show that economic growth has long-term relationship with the macroeconomic instability In other words; changes in macroeconomic instability indexes will be associated with the increase (decrease) of economic growth in the long run. Also, the results show that although population growth rate is effective on the long-term economic growth, it is not influenced by the very itself.

In fact, this variable is weak in comparison with other exogenous variables in the short run.

On the other hand, public and private sector investment ratio to GDP and human capital development index have positive effect on the economic growth rate. The estimated 
adjustment coefficients show that economic growth rate is adjusted to its imbalance with 5\% coefficient.

According to the obtained results and remarkable inhibitory effect of the macroeconomic instability on the real growth rate, it seems that the government should consider macroeconomic instability and use purposeful and controlled policies to reduce macroeconomic instability, because, remarkable decrease of he economic growth is the detrimental outcome of the macroeconomic instability in the long term.

To achieve a sustainable economic growth, setting up and safeguarding an environment with macroeconomic stability is necessary and sustainable growth requires imposition of the policies which are not led to the accelerating and increasing inflation, chronic budget deficit, uncontrollable financial supply current account deficit and apparent change of exchange rate.

The poor management of macroeconomic with the adoption of incorrect and illogical fiscal and monetary policies and passive reaction against shocks will intensify the macroeconomic instability. The way of reaction to the shocks is very important.

Financial disciplinary in the budget is the most important move in order to set up and safeguard macroeconomic stability. This issue requires revising in regulation of public budget based on oil and gas revenues.

Since shocks destabilize macroeconomic environment continually, it is recommended that the government should always consider: reducing governmental expenses, increasing its efficiency, resisting against increasing demands of the governmental organizations, improving tax system, stabilizing monetary policy and efficient management of credit facilities.

\section{References}

Ames, B., Brown, W., Ddevarajan, S., \& Izquierd, A. (2003). A source book for poverty reduction strategies. Washington D.C.: World Bank.

Barati, M, A. (2008). Investigation of economic instability and economic vulnerability indices in Iran. Tadbire eghtesad institute.

Barro, R, J. (2000). Inequality and Growth in a Panel of Countries. Journal of Economic Growth, 5.

Cottani, J, A., Cavallo, D.F., \& Khan, M.S. (1990). Real Exchange Rate Behavior and Economic Performance in LDCs. Economic Development and Cultural Change, 39(1).

Dhnote, P., \& Kapur, I. (1997). Towards a Market Economy: Structure of Government. IMF Working Paper. 11.

Doronbush, R., \& Fischer, S. (1999). Macroeconomics. Soroush Publications.

Fischer, Stanley. (1993). The Role of Macroeconomic Factors in Growth. Journal of Monetary Economics, 32. 
Fuentes, R., Larrain, M., \& Schmith-Hebbel, K. (2006). Source of Growth and Behavior of TFP on Chile. Cuadernos De Economia, 43.

Ghura,D. (1995). Macro Policies, External Forces and Economic Growth in Sub-Sahara Africa. Economic Development and Cultural Change, 43(4).

Gregorio, J. De. (1995). The Effect of Inflation on Economic Growth: Lessons from Latin America. IMF Working Paper. 95.

Hadjimicheal, M. T., Dhaneshwar G., Martin M., Roger N., \& Ucer E. M. (1994). Effects of Macroeconomic Stability on Growth, Saving and Investment in Sub-Saharan Africa: An Empirical Investigation. IMF Working Paper. 98.

Hausmann, R., \& Gavin, M. (1996). Securing stability and growth in a shock prone regione. The policy challenge for Latin America. Inter-American Development Bank.

Ismihan, M. (2003). The Role of Politics and Instability and Public Spending Dynamics and Macroeconomic Performance: Theory and Evidence from Turkey. PH.D Thesis, METU, Ankara.

Jaramillo, L., \& Sancak, C. (2007). Growth in the Dominican Republic and Haiti: Why has the Grass Been Greener on One Side of Hispaniola? IMF Working Paper.

Khalili Araqi, M., \& Ramezanpour, E. (2001). Significance of Environment with Macroeconomic Stability. Economic Research Journal, 58.

Knight, M., Loayaza, N., \& Villanueva, D. (1993). Testing The Neoclassical Theory of Economic Growth. IMF Staff Papers, 40(3).

Mankiw, N.D., Romer, P., \& D. Weil. (1992). A Contribution to the Empirics of Economic Growth. Quarterly Journal of Economics, CVII.

Nofersti, M. (1999). Unit Root and Co-Integration in Econometrics. Rasa Cultural Services.

North, D. (1999). Institutions, Institutional Changes and Economic Performance. Publication of Plan and Budget Organization.

Oshikoya, T. (1994). Macroeconomic Determinants of Domestic Private Investment in Africa: An Emprical Analaysis. Economic Development abd Cultural Change, 42(3).

Pesaran, M. H., \& Shin, Y. (1998). Impulse response analysis in linear multivariate models. Economic Letters, 58.

Romer, M. (1986). Increasing Return and Long Run-Term Growth. Journal of Political Economy, 94.

Sahay, R., \& Goyal, R. (2006). Volatility and Growth in Latin America. IMF Working Paper.

Turtelboom, B. (1991). Interest Rate Liberalization: Some Lessons from Africa. IMF Working Paper, 121. 
Notes

Note 1. Real Exchange Rate is multiplication of implicit index ratio of imports rate to the consumer services and goods price index in exchange rate of informal market.

Note 2. Exchange relationship is the proportion of implicit index of exports price to the implicit index of imports price.

\section{Copyright Disclaimer}

Copyright reserved by the author(s).

This article is an open-access article distributed under the terms and conditions of the Creative Commons Attribution license (http://creativecommons.org/licenses/by/3.0/). 